\title{
A RBSD COMO ESPAÇO DE PESQUISA SOCIOLÓGICA DO DIREITO: HOMENAGEM A FERNANDO RISTER
}

Artur Stamford da Silva (Editor)

A importância e a necessidade de um espaço para divulgar o pensar sociologicamente o direito ficam evidenciadas a cada publicação da Revista Brasileira de Sociologia do Direito (RBSD), da Associação Brasileira de Pesquisadores em Sociologia do Direito ABraSD (www.abrasd.com.br).

Cada novo número e volume da RBSD demonstra que as reflexões nacionais e internacionais da sociologia do direito são indispensáveis para observar o direito local, regional, nacional, internacional, paraestatal, multinível, portanto o direito das sociedades locais e da sociedade mundial. É o que se pode ler nas reflexões dos autores nacionais e internacionais publicados aqui na RBSD, Revista que, inclusive, não tem diretriz gnosiológica nem epistemológica, o que viabiliza pesquisas científicas das mais variadas concepções terem lugar, exigindo para tanto que o teor seja científico e não de cunho parecerista, opinativo.

Ainda que a RBSD não tenha o nem um conceito determinado de ciência, ela acata a ideia de o saber científico não se confundir com outros modos de conhecimento. Distinção esta pautada pela liberdade de pensar e refletir sobre a relação entre o direito e as questões e situações da vida em sociedade.

É nessa perspectiva que seguimos com o desafio de dar continuidade e seguimento à divulgação do pensar sociologicamente o direito sem cair na tentação de produzir mentores intelectuais, de transformar esse espaço em mais um veículo de constituição de donos do saber, mas sim como ponte para a diversidade de olhar, de observar o direito como elemento do social. 
O volume 3, número 1, da Revista Brasileira de Sociologia do Direito (RBSD) está voltado a homenagear a dedicação, a abdicação, o empenho, os esforços e tantos outros adjetivos positivos do Editor Fernando Rister de Sousa Lima, responsável pela RBSD desde sua criação em 2013 publicando os volumes 1 e 2, nos anos de 2014 e 2015. Infelizmente, motivos pessoais, levaram Fernando Rister, pai de Alice, no início do ano de 2016, a informar ao então Presidente da ABraSD, Artur Stamford da Silva, seu afastamento da Editoração da RBSD.

Nas palavras de Rister (RBSD, v. 2, n.2, de 2015):

agradece-se à Presidência da Associação Brasileira de Pesquisadores em Sociologia do Direito (ABraSD) pela indicação para a função de Editor-chefe, nominalmente ao então Presidente, o professor doutor Marcelo Pereira Mello e ao atual Presidente, o professor doutor Artur Stamford da Silva, função esta que encerro com este número, mas, não sem consignar os meus efusivos votos de que os próximos editores possam levar adiante este auspicioso projeto de publicar a Revista Brasileira de Sociologia do Direito (RBSD) com zelo e, sobretudo, preocupação com o papel histórico que poderá ou não ser outorgado ao periódico.

Findo o VII Congresso ABraSD, realizado de 18 a 20 de maio de 2016, o Presidente eleito da ABraSD, José Rodrigo Rodriguez, tratou do assunto. Contatado, antes de aceitar, voltei a consultar Fernando Rister sobre o quanto sua decisão era decisivamente definitiva. Ao receber resposta positiva, declarei ao Presidente que assumiria a RBSD. Escrevo esse histórico para registro da história da ABraSD e da RBSD.

As experiências e declarações de apoio e de suporte dadas por Fernando Rister e por José Rodrigo Rodriguez foram fundamentais para minha decisão com pleno conhecimento dos desafios por vir para a RBSD seguir sua trajetória fazendo história da sociologia do direito no âmbito nacional e no internacional.

Assim, homenagear Fernando Rister neste volume é registrar a importância e a dívida que todos temos por existir a RBSD.

Com acesso aberto a todo seu conteúdo, por entender que informação e conhecimento são bens sociais que devem poder ser acessado por todos em iguais 
condições, a RBSD está disponível gratuitamente na página da ABraSD (http://www.abrasd.com.br/\#!rbsd/cjg9) bem como em http://revista.abrasd.com.br/index.php/rbsd/index. Integrante do sistema OJS (Open Journal System) e com D.O.I. (Digital Object Identifier), passamos a requer a indexação da RBSD em diversos indexadores.

Agradeço a dedicação da Editora de Texto Sueli Aragão e da Editora de Layout Carolina Leal Pires, sem as quais este volume não teria sido publicado.

Agradeço a todos os avaliadores integrantes do Conselho Editorial e pareceristas externos pela demonstração de compromisso com o projeto da RBSD/ABraSD. A maneira como acataram minhas súplicas por urgência nos pareceres, promovendo-os em curtíssimo tempo, foi fundamental para a garantia da qualidade dos trabalhos que integram esta publicação e, portanto, para nossa segurança que seguimos com o padrão de qualidade da RBSD.

Agradeço, igualmente, a todos e a cada um que depositou confiança na RBSD como um periódico merecedor de divulgação de suas pesquisas. Enfatizo essa confiança porque os trabalhos foram submetidos sem que a RBSD sequer tivesse QUALIS, afinal só se pode requerer avaliação havendo dois anos de publicações. Só em 2016 a RBSD pôde requerer avaliação pelo Comitê de Área da CAPES, o que foi devidamente providenciado e estamos na expectativa de recebermos uma boa qualificação.

Por fim, agradeço ao prof. Dr. Andreas Fischer-Lescano o envio de artigo inédito de sua autoria, artigo que amplia nossa reponsabilidade e reforça a importância de um periódico brasileiro com inserção internacional. Sigamos com a RBSD e seus desafios.

Como homenagem a Rister, o primeiro artigo registra um caminho para se trabalhar a arte o direito, o direito e a literatura cientificamente. Não só porque a cada afirmação o autor expõe sua fonte de informação, mas principalmente por apresentar seu olhar expondo a literatura como dados de pesquisa. Poderia Fischer-Lescano se resumir com a frase "Kafka foi o crítico mais radical da prática jurídica". Contudo, a afirmação é 
sustentada com exposição da obra de Kafka e de vários comentaristas dela. A contribuição se amplia para além da metodologia realizada no trabalho de Fischer-Lescano ao lançar a concepção que a crítica à pratica jurídica não implica descrédito no direito, antes, o olhar crítico é quanto à relação do direito com o poder estatal e com a violência, todavia, Kafka é um crítico confiante na construção de um direito justo. Os autores explorados e a metodologia empregada exemplificam o lugar de uma pesquisa teórica, bibliográfica, de qualidade.

O segundo trabalho é a aposta dos autores João Paulo Allain Teixeira e Raquel Fabiana Lopes Sparemberger na RBSD. Oferecem ao nosso leitor reflexões sobre práticas constitucionais contemporâneas observadas no continente europeu e no continente latino-americano, para apresentar resultado de pesquisa sobre caminhos e diálogos vivenciados nesses continentes. A pesquisa explora o movimento chamado "novo constitucionalismo latino americano" e relaciona às vivências europeias com o neoconstitucionalismo, também conhecido como constitucionalismo sociológico. Antropólogos, sociólogos e juristas são citados, o que revela a MITdisciplinariedade da pesquisa. Ao tensionar o tema da "dignidade da pessoa humana", os autores lançam à reflexão a insuficiência do pluralismo jurídico clássico europeu para discutir as novidades do novo constitucionalismo latino americano, um espaço de construção semântica, afinal "as novas Constituições trazem mudanças que abrangem não só a questão cultural e os direitos coletivos, mas mudanças nos sistemas políticos e jurídicos".

Seguindo nossa homenagem a Fernando Rister, nada mais condizente que reflexões sobre trabalho. Everaldo Gaspar Lopes de Andrade e Isabele Bandeira de Moraes D'Angelo põe em diálogo a teoria jurídico-trabalhista crítica com as teorias dos movimentos sociais lançando fundamentos para um olhar sobre vivências do "mundo do trabalho". Após apesentar os nortes metodológicos dessa perspectiva, o texto serve de exemplo para uma distinção entre ciência e outros saberes. A concepção crítica não está reduzida a uma seita fundamentalista, antes se apresenta como olhar em diálogo com perspectivas outras, 
inclusive a dogmática do direito, afinal "Na medida em que a teoria jurídico-trabalhista crítica estabelece um diálogo com os outros ramos dos chamados saberes sociais ou culturais, é possível reconfigurar o objeto deste ramo do direito, a partir da prevalência do trabalho como ontologia do ser social, para que prevaleça, como seu objeto, o trabalho propriamente livre". Ainda que voltado a uma reflexão teórica, os autores não deixam de apresentar casos de situações vivenciadas nos Estados Unidos, na França, na Alemanha e na América Latina, afinal, não há teoria sem prática nem prática sem teoria.

Ainda sobre a questão trabalhista, Vanessa Rocha Ferreira consolida o lugar da reflexão sociológica do direito com sua pesquisa sobre "O dano existencial nas relações de trabalho e a eficácia horizontal dos direitos fundamentais nas relações privadas", afinal a realidade do cotidiano trabalhista, especificamente as situações vivenciadas de trabalho excessivo, desrespeito às limitações da jornada de trabalho prevista na legislação são desafios que batem constantemente à porta do direito reclamando justiça. Poderia se pensar que o direito não tem alcance para lidar com complexa situação social. Não é o que resulta da pesquisa de Vanessa Rocha Ferreira. Citando autores europeus, estadunidenses, latino americanos e brasileiros, a pesquisa se apresenta como demonstração do não isolamento teórico nem da subordinação latino americana ao olhar teórico colonizador. As decisões jurídicas trabalhadas caracterizam o lugar da sociologia do direito como olhar capaz de lidar com a legitimidade da decisão judicial. Se a conclusão vem carregada de expressões como "devemos respeitar a dignidade da pessoa humana no ambiente laboral. Eis o papel do direito do trabalho: proteger os direitos básicos dos trabalhadores de modo a assegurar-lhes um trabalho digno, com qualidade, sem extrapolar os limites estabelecidos pelo ordenamento jurídico vigente, respeitando a sua dignidade como ser humano, e consequentemente, os seus direitos fundamentais", a frase não soa como frase de efeito ao leitor que observou a metodologia aplicada na pesquisa.

Luiz Felipe Monsores Assumpção segue o mote trabalhista com sua pesquisa sobre a inspeção do trabalho, analisando o "processo de transformação do Sistema de Inspeção do 
Trabalho". Igualmente citando autores nacionais e internacionais, apresenta dados da realidade trabalhista e das inspeções do trabalho, portanto, mantendo nossa insistência na impossibilidade de haver teoria sem prática e prática sem teoria. Constituição de 1988, mudanças nas lideranças políticas e a profissionalização de inspetores do trabalho e consequente produtivismo na fiscalização do trabalho. Criticar os dez anos de reestruturação da inspeção do trabalho e analisar o estágio atual apresentando alternativas e não apenas lançando problemas foi o desafio realizado pelo autor. Chama atenção que a observação participativa, pois o autor é fiscal do trabalho não aparece como fator que inviabiliza a análise sociológica do problema, antes, se apresenta mais como elemento propulsor e facilitador da obtenção dos dados e da fluência na sua análise. Conta, portanto, este como um texto metodologicamente importante para a percepção do cuidado com falar a partir de dados e não tomando sua pesquisa como espaço para externar olhares subjetivos. Luiz Felipe Monsores Assumpção consegue desenvolver sua pesquisa, analisar seus dados sem cair na tentação de tornar seu texto um artigo de opinião.

Ainda que em andamento, a pesquisa Flávia Almeida Pita expõe observações de questões vivenciadas por incubadas da Incubadora de Iniciativas da Economia Popular e Solidária da UEFS - IEPS-UEFS para sua formalização. A exigência de formalização das incubadas promovem dificuldades e impedem o desenvolvimento de alternativas aos que lidam com "Economia Social, Alternativa, Invisível, Subalterna, Periférica, Solidária, Economia Popular Solidária". Com criatividade reflexiva, Flávia Pita lança ao debate, partindo da leitura de Quijano e sua "colonialidade do poder" para apresentar caminhos a uma decolonialidade do direito (decolonialidade jurídica). Assim, a análise dos dados coletados na Incubadora levaram a autora a concluir pela necessidade da implementação de uma lógica própria dessa realidade econômica para incentivar e promover a realização de atividades da economia popular como alternativa à precarização do trabalho. 
Seguindo nossa homenagem, um texto sobre educação. Rafael da Silva Mattos, Wecisley Ribeiro do Espírito Santo, Juliana Brandão Pinto de Castro, Jeferson Moebus Retondar, Leonardo Hernandes Oliveira e Stephany Nascimento apresentam suas leituras sobre a lógica da mercantilização da educação para analisar o projeto "Uma Ponte para o Futuro", publicado pelo Partido do Movimento Democrático Brasileiro (PMDB), em 29 de outubro de 2015. A explícita indignação com essa mercantilização não retira a qualidade de pesquisa, pois a análise não se reduz a trabalhar os dados com avidez, mas sim com a acuidade esperada e exigida numa pesquisa científica. O documento é analisado e tratado considerando dados econômicos, o IDH do Brasil, a importância da educação no âmbito internacional, além do conteúdo do documento. A conclusão é que se se insistir em promover uma política publica que trata educação com mercancia, o Brasil cairá num processo de regressão quanto aos avanços na área da educação até aqui conquistados.

Fechando este volume, dois trabalhos que enfatizam o mote da ABraSD não ser um espaço de autoridades, um espaço exclusivo de doutores e formador de excelências e deuses da sociologia do direito, mas um espaço de integração e divulgação de pesquisas científicas realizadas por pesquisadores.

Desirée Cavalcante Ferreira traz mais uma demonstração da relação teoria e prática e da capacidade de se fazer pesquisa antes mesmo de obter o título de doutor. O tema da democracia e da decisão judicial, da política judiciária, da legitimidade do Supremo Tribunal Federal está trabalhado a partir de dados catalogados sobre o cotidiano do STF, bem como do processo de nomeação de seus ministros. Parte a autora da teoria do diálogo institucional para debater a judicialização da política, politização da justiça e ativismo judicial, portanto, a relação decisão judicial e política, entre decisões do legislativo e decisões do judiciário. O controle de constitucionalidade é debatido a partir da dicotomia jurisdição constitucional forte e uma fraca. Ocorre que essas duas perspectivas se apresentam limitadas para uma resposta à "encruzilhada da separação dos poderes". As reflexões da autora apontam como debates teóricos lidam com situações cotidianas, da 
vida em sociedade, no caso da pesquisa de Desirée Cavalcanti Ferreira o problema do poder e uma leitura de pauta hierárquica para o tema. Ainda que sem conclusão, a pesquisa revela a necessidade e importância de se romper com "as teorias da última palavra" afinal não se pode atribuir a um único órgão o monopólio da "última palavra" em matéria constitucional.

Por fim, Vinícius Leão de Castro, Alana Ramos de Araújo e Laryssa Mayara Alves de Almeida, a partir da concepção de biopder, em Michel Foucault, desenvolvem reflexões sobre a interferência de políticas públicas no cotidiano da população. Além de apresentar a base teórica, os dados empíricos foram catalogados em situações vividas no Brasil. A pesquisa lida com o discurso higienista utilizado em diversas campanhas de saúde pública, como nas campanhas de vacinação em massa e nas "brigadas mata-mosquito", responsáveis por exterminar a febre amarela. A revolta da vacina é apontada como reação à política pública, portanto, como caso de perda da liberdade e realização de mudança social por imposição do poder instituído. A pesquisa segue com o argumento que situações da vida atual podem ser observadas e pensadas a partir do caso da política de higienização e a revolta da vacina. Para isso, pontuam casos referentes à alimentação, ao sexo e à Internet. Expostos os dados, eles são analisados quanto à liberdade de escolha, de atuação de cada indivíduo e quanto à participação na constituição do estatuto de verdade de uma determinada sociedade. A conclusão é que a microfísica do poder é exercida dentro dos limites impostos pelo poder estatal, como demonstrado com vivência nos casos de políticas públicas, ao mesmo tempo em que há a subjetividade, como se pode observar das reações desempenhadas por "sujeitos livres nas relações de poder que atravessam as práticas sociais.

Termino aqui minha homenagem a Fernando Rister com a esperança de não frustrar e conseguir manter a qualidade da RBSD.

Sigamos em pesquisa científica! 